\title{
Microanalytical characterization of nineteenth century Portuguese Paintings: contribution to the study of works by João Cristino da Silva and Miguel Ângelo Lupi
}

Bordalo, R. , Lorena, M*, Cardoso, A. ${ }^{*}$, Mirão, J. , Santos, L. ${ }^{* *}$ and Candeias, A.

* Laboratório HERCULES, Universidade de Évora, Palácio do Vimioso, Largo Marquês de Marialva, 8, 7000-809 Évora, PORTUGAL

** Laboratório José de Figueiredo, Direção Geral do Património Cultural, Rua das Janelas Verdes, 37, 1300001 Lisbon, PORTUGAL

*** Instituto Superior Técnico, Av. Rovisco Pais, 1, 1049-001 Lisbon, PORTUGAL

Email: rmbordalo@uevora.pt

The nineteenth century was a very prolific artistic era during which the materials used by painters changed radically. The use of new paint materials developed during that period depended greatly from the painter's own preference and color taste. Nevertheless, the adoption of new materials was not immediate throughout Europe but gradual since it depended on its commercial availability in each country. Thus, the use of a particular material is not only of high importance for the study of the painter technique but also to the study of the dissemination of the new materials in the Western world. The systematic study of the painting materials and their use in the nineteenth century in Portugal is still to be made since it was a period of great transformation and from which only few painters and paintings have been already materially characterized. The present paper contributes to the study of the painting materials used by Portuguese painters in the nineteenth century. It describes the comparative microanalytical characterization performed on four paintings currently exhibited at the National Museum of Contemporary Art (Chiado Museum) in Lisbon. The oil paintings, dated from 1855 to 1879, comprise two works by Miguel Ângelo Lupi (1826-1883) and two by João Cristino da Silva (1829-1877), two important Portuguese painters of the Romanticism whose palette has not been previously studied.

The characterization of the painting materials was performed using an optical microscope LEICA DM2500M, a scanning electron microscope of variable vacuum HITACHI 3700N coupled with an energydispersive X-R spectrometer BRUKER Xflash 5010SDD, a $\mu$-Raman HORIBA Xplora coupled with an Olympus BX41 microscope and a $\mu$-FTIR Nicolet Nexus 670 FTIR with Continuum IR microscope.

The study first allowed the characterization of each painter's technique through the analysis of the painting's cross-sections. Figure 1 shows the multiple layers - ground and paint layers - and respective thickness the painter used during his creative process. $\mu$-Raman and $\mu$-FTIR data allowed the identification of the painting materials used by the painters such as Prussian blue, azurite, lead white, barium white, zinc white, vermillion (Fig. 2), carbon and bone black, calcium carbonate and ochre.

This study allowed not only to characterize for the first time the palette of Cristino da Silva and Miguel Ângelo Lupi but also to contribute to the study of the use of pictorial materials in Portugal in the nineteenth century.

The authors acknowledge National Museum of Contemporary Art (Chiado Museum) and Fundação para a Ciência e a Tecnologia for the grant SFRH/BPD/85259/2012. 


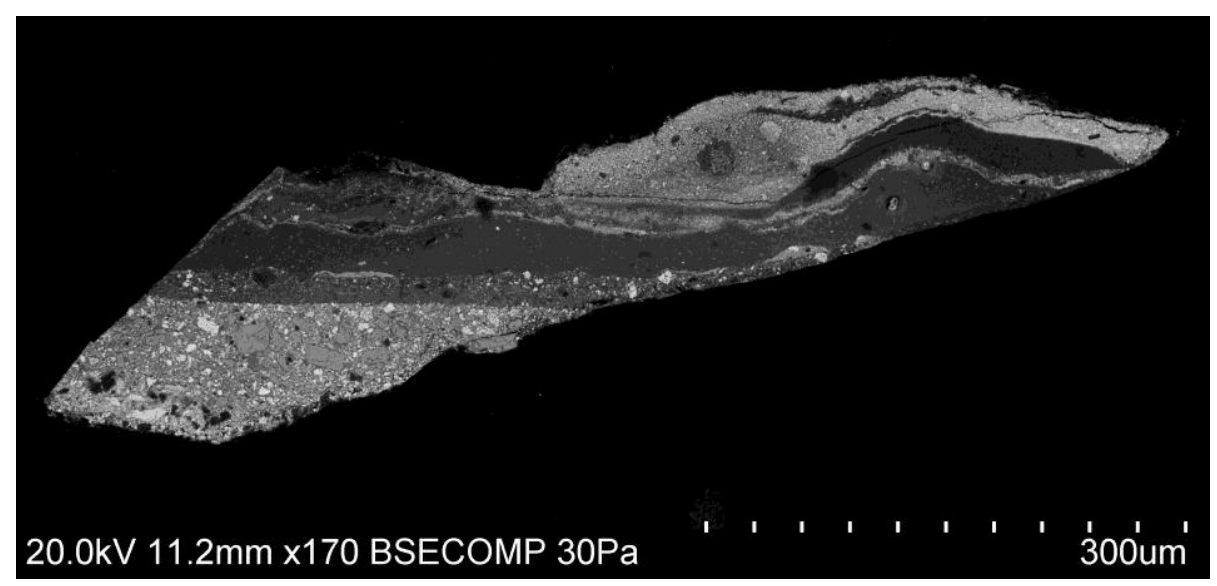

Figure 1. Microphotograph of a sample taken from Retrato da Viscondessa de Castilho (1874) by Miguel Ângelo Lupi.

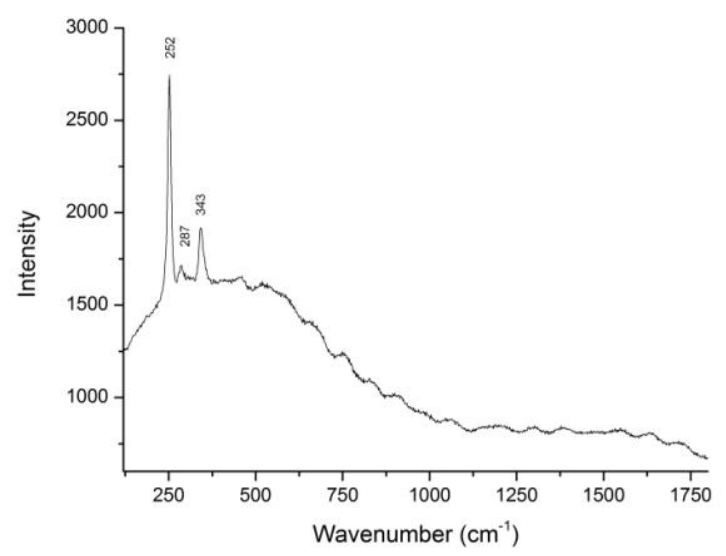

Figure 2. $\mu$-Raman spectrum of Vermilion (785 nm excitation wavelength) from Marinha (1855-60) by Cristino da Silva. 